${ }^{1}$ Mona Mohamed-Kamal Hijazi

\title{
The effect of visual and verbal feedback on the quality of fencing technique
}

\author{
${ }^{1}$ Assistant Professor of fencing, Faculty of Physical Education, Sadat City University, Egypt
}

\begin{abstract}
This research aimed to identify the effect of using visual feedback (expert model, personal model) and verbal feedback on the level of performance of some skills in fencing. The researcher used the experimental method by using pre and post measurements for three experimental groups, on a sample of (40) second year female students on the Faculty of Physical Education, Sadat City University (10) for the survey study, (30) for the basic study were divided into three experimental groups, Each group consists of (10) students. The first experimental group used visual feedback technique using "expert modeling", the second, used visual feedback technique using "Self-Modeling" and the third, verbal feedback was used. There were statistically significant differences between the visual group using the (expert modeling) and the verbal group in the (basic skills - offensive skills - Total skill performance) in the direction of the visual group using (expert modeling). There were also statistically significant differences between the visual group using (personal modeling) and the verbal group in both (basic skills - defense skills - skill level) in the direction of the visual group using the (personal modeling). While there were no statistically significant differences between the two groups using visual feedback (the expert model, the personal model) in all search variables.
\end{abstract}

Keywords: visual feedback, verbal feedback, expert modeling, personal modeling, fencing.

\section{Introduction}

Sensory information that is provided to the learner is one of the most important variables affecting motor learning. The amount of this information, type, method and timing of the display significantly affect learning and performance, this information is divided into two types, the first type is "pre-feeding" and represents information that precedes performance, the second type of information is given during and after performance, which is known as "feedback", is to provide the individual with different movement, and this type of correction called "external feedback".

Feedback is the ability to provide the performer with information during and after performance that helps him assess his performance (Hossam El-Din, T., Abdel-Shakour, M., Helmi, M., 2014: 84). It is vital information about our performance. By using feedback, we can analyze and improve our performances. We receive feedback from two sources, first, "Internal feedback" which comes to us from our senses. The proprioceptors in our joints tell us 
how the movement felt, and our eyes tell us whether we were successful. Second, "External feedback" which comes to us, for example, by watching ourselves on video, listening to our coach or being given our score (Beashel, P., Sibson, A., Taylor, J., 2001, 115).

The education process directly needs to choose the appropriate method for the feedback, and the teacher plays the main role in choosing the appropriate method according to the nature of the educational material and the level of the students, it is the responsibility of him to deliver the appropriate information to complete the educational process, In addition, choosing the appropriate type of information helps in Reaching the required level of performance, and it also contributes to increasing the level of learner motivation.

Feedback depends, primarily, on the ability and experience of the players. Beginners need only a small amount of verbal, or visual feedback. They find it difficult to use internal feelings about their performance and they handle a great deal of detailed information. More experienced performers get the "feel" of successful movements. They can then rely more on internal feedback backed up by their coach's observations (Beashel, P., Sibson, A., Taylor, J., 2001, 115).
The research on feedback precision suggests that extrinsic feedback does not need to be extremely precise to be effective. This is particularly true during early learning, when athletes are just trying to get a general idea of the correct relative timing pattern. At that point, all they need to know is general information about the relative amount and direction of their errors. You might tell a beginning high jumper that her takeoff was a bit too early. However, once she achieves a higher level of technical skill, the athlete would benefit from more precise feedback that helps her finetune her movements (e.g., the duration in milliseconds of her final two steps) (Wrisberg, C., 2007, 123).

information on the efficiency of performance, and thus helps the learner to understand the validity of the performance "technical", and the extent to achieve the ultimate goal of the skill or not.

In the case of beginners and people who are not familiar with the new skills they are unable to visualize the movement, and then resort to access to information for correction through external sources, which help to modify the course of his subsequent

Hence the importance of research, and the need for it in helping teachers and students to choose the most appropriate feedback methods, in education and 
training for some basic skills, which is the basis of the rest of the offensive and defensive skills of fencing.

The researcher noticed that the use of feedback is not based on scientific method, where methods are mixed to provide feedback, there is also no proper choice that fits the type of skills provided to the student as a beginner in this activity, as the type of feedback suitable for beginners differs from those with an advanced level, where proper technique helps achieve good technical performance of skills. Therefore, the researcher considered the need to study the effect of using visual and verbal feedback on the technical performance of fencing skills among students of the Faculty of Physical Education in Sadat City.

\section{Aim of the study:}

This study aimed to identify the effect of using visual feedback (expert model, personal model) and verbal feedback on the quality of fencing technique for female students on the Faculty of Physical Education, Sadat City University.

\section{Hypotheses of the study:}

- There are significant differences between the averages of pre and post measurements for each of the three experimental groups in the direction of post measurements in the research variables.

- There are significant differences between the averages of post measurements for the three experimental groups in the research variables.

\section{Materials and Methods}

\section{Data collection}

- (2) JVC Camera

- A computer connected to a Display Screen.

- Kinovea program for kinetic analysis.

\section{Study method}

The researcher used the experimental method by using pre and post measurements for three experimental groups.

\section{Participants}

Participants were (40) second year female students on the Faculty of Physical Education, Sadat City University for the academic year 2017/2018, (10) for the survey study, (30) for the basic study were divided into three experimental groups, Each of them consists of (10) students. The first experimental group used visual feedback technique using "expert modeling", the second, used visual feedback technique using "SelfModeling" and the third, verbal feedback was used.

The skewness coefficient of the research variables was between $(\cdot, r\urcorner \wedge)$ and $(1, r 90)$ which indicates moderating of distribution, and there are no significant differences between each of the three 
experimental groups in the pre measurements which indicates equality of the three groups in the research variables (basic skills, Offensive skills, and Defensive skills)

\section{Research procedures:}

\section{Survey study}

The researcher conducted the survey study on a sample of 10 female students from the same research community and outside the research participants in the period from February $1 \%$, to February $1 \varepsilon$, 2018, for the purpose of ensure that the place appropriate, Ensure the quality of the devices used in the imaging and visual display, Determination of dimensions, distances and height of cameras and field of photography for each skill.

\section{Pre- measurements:}

Pre- measurements were conducted for a sample in basic research February 20, 2018, they included:

- Measuring the quality of fencing technique for students:

- Basic skills (On Gard, Advance, Retraite, Development)

- Offensive skills (Simple Attack, Compound Attack, Simple Riposte, Compound Riposte)
- Defensive skills (Simple Parry, Semi- Circular Parry, Circular Parry, Diagonal Parry).

\section{Implementation of the program:}

The educational program was applied using visual feedback (expert model - personal model), verbal feedback, on the three research groups, from February 27, 2018 to April 23, 2018, once a week (an average of two hours according to the number of hours allocated to the course), the program lasted weeks.

\section{Post measurements:}

Post measurements were conducted on April 24, 2018. The performance was evaluated by a committee of evaluators, consisting of three fencing professors, according to the method used to evaluate the skills performance of students in the college. The average score was calculated for the three evaluators. 


\section{RESULTS}

Table (1) Significant differences between pre and post measurements for the Visual Group (Expert Modeling) in skill performance components

\begin{tabular}{lcccccccc}
\hline \multirow{2}{*}{ Variable } & \multicolumn{2}{c}{ Pretest } & \multicolumn{2}{c}{ Post test } & & Ratio \\
\cline { 2 - 8 } & Mean & $\begin{array}{l}\text { Std. } \\
\text { Deviation }\end{array}$ & Mean & $\begin{array}{l}\text { Std. } \\
\text { Deviation }\end{array}$ & $\begin{array}{l}\text { Sig. } \\
\text { tailed) }\end{array}$ \\
\hline basic skills & 4.20 & .789 & 7.30 & 1.059 & $73.81 \%$ & 9.858 & .000 \\
\hline Offensive skills & 3.50 & .527 & 7.60 & 1.174 & $117.14 \%$ & 17.571 & .000 \\
\hline Defensive skills & 3.70 & .949 & 7.40 & .843 & $100.00 \%$ & 24.222 & .000 \\
\hline $\begin{array}{l}\text { Total } \\
\text { performance }\end{array}$ & 11.40 & 2.011 & 22.30 & 2.669 & $95.61 \%$ & 31.321 & .000 \\
\hline
\end{tabular}

Table (1) shows that there are statistically significant differences between pre and post measurements for the Visual Group (Expert Modeling) in the skill performance components. And the rates of changes between pre and post measurements in skill performance components ranged from $73.81 \%$ to $117.14 \%$.

Table (2) Significant differences between pre and post measurements for the Visual Group (Self-Modeling) in skill performance components

\begin{tabular}{|c|c|c|c|c|c|c|c|}
\hline \multirow[b]{2}{*}{ Variable } & \multicolumn{2}{|c|}{ Pretest } & \multicolumn{2}{|c|}{ Post test } & \multirow{2}{*}{$\begin{array}{l}\text { Ratio } \\
\text { Change }\end{array}$} & \multirow[b]{2}{*}{$\mathrm{t}$} & \multirow{2}{*}{$\begin{array}{l}\text { Sig. }(2- \\
\text { tailed })\end{array}$} \\
\hline & Mean & $\begin{array}{l}\text { Std. } \\
\text { Deviation }\end{array}$ & Mean & $\begin{array}{l}\text { Std. } \\
\text { Deviation }\end{array}$ & & & \\
\hline basic skills & 4.20 & 1.033 & 7.20 & .789 & $71.43 \%$ & 11.619 & .000 \\
\hline Offensive skills & 3.90 & .738 & 6.80 & .632 & $74.36 \%$ & 16.155 & .000 \\
\hline Defensive skills & 3.30 & .483 & 7.70 & .823 & $133.33 \%$ & 16.500 & .000 \\
\hline $\begin{array}{l}\text { Total skill } \\
\text { performance }\end{array}$ & 11.40 & 1.776 & 21.70 & 1.889 & $90.35 \%$ & 26.022 & .000 \\
\hline
\end{tabular}

Table (2) shows that there are statistically significant differences between pre and post measurements for the Visual Group (Self-Modeling) in the skill performance components. And the rates of changes between pre and post measurements in skill performance components ranged from $71.43 \%$ to $133.33 \%$.

Table (3) Significant differences between pre and post measurements for the Verbal Group in skill performance components

\begin{tabular}{|c|c|c|c|c|c|c|c|}
\hline \multirow[b]{2}{*}{ Variable } & \multicolumn{2}{|c|}{ Pretest } & \multicolumn{2}{|c|}{ Post test } & \multirow{2}{*}{$\begin{array}{l}\text { Ratio } \\
\text { Change }\end{array}$} & \multirow[b]{2}{*}{$\mathrm{t}$} & \multirow{2}{*}{$\begin{array}{l}\text { Sig. } \quad(2- \\
\text { tailed) }\end{array}$} \\
\hline & Mean & $\begin{array}{l}\text { Std. } \\
\text { Deviation }\end{array}$ & Mean & $\begin{array}{l}\text { Std. } \\
\text { Deviation }\end{array}$ & & & \\
\hline basic skills & 3.80 & 1.033 & 6.20 & .632 & $63.16 \%$ & 9.000 & .000 \\
\hline Offensive skills & 3.80 & .632 & 6.50 & .707 & $71.05 \%$ & 10.371 & .000 \\
\hline
\end{tabular}


journal of Theories and Applications of physical education sport sciences

ISSN : 2636-3925

Vol, (3) Issue, (1) July 2020

\begin{tabular}{|c|c|c|c|c|c|c|c|}
\hline Defensive skills & 3.40 & .699 & 6.60 & .843 & $94.12 \%$ & 12.829 & .000 \\
\hline $\begin{array}{ll}\text { Total } & \text { skill } \\
\text { performance } & \end{array}$ & 11.00 & 2.160 & 19.30 & 1.636 & $75.45 \%$ & 19.624 & .000 \\
\hline
\end{tabular}

Table (3) shows that there are statistically significant differences between pre and post measurements for the Verbal Group in the skill performance components. And the rates of changes between pre and post measurements in skill performance components ranged from $63.16 \%$ to $94.12 \%$.

Table (4) The differences between research groups in post measurements

\begin{tabular}{|c|c|c|c|c|c|c|}
\hline Variable & & Sum of Squares & $\mathrm{df}$ & Mean Square & $\mathrm{F}$ & Sig. \\
\hline \multirow{3}{*}{ basic skills } & Between Groups & 7.400 & 2 & 3.700 & 5.176 & .013 \\
\hline & Within Groups & 19.300 & 27 & .715 & & \\
\hline & Total & 26.700 & 29 & & & \\
\hline \multirow{3}{*}{ Offensive skills } & Between Groups & 6.467 & 2 & 3.233 & 4.259 & .025 \\
\hline & Within Groups & 20.500 & 27 & .759 & & \\
\hline & Total & 26.967 & 29 & & & \\
\hline \multirow{3}{*}{ Defensive skills } & Between Groups & 6.467 & 2 & 3.233 & 4.619 & .019 \\
\hline & Within Groups & 18.900 & 27 & .700 & & \\
\hline & Total & 25.367 & 29 & & & \\
\hline \multirow{3}{*}{$\begin{array}{l}\text { Total } \\
\text { performance }\end{array}$} & Between Groups & 50.400 & 2 & 25.200 & 5.656 & .009 \\
\hline & Within Groups & 120.300 & 27 & 4.456 & & \\
\hline & Total & 170.700 & 29 & & & \\
\hline
\end{tabular}

Table (5) The significance of differences between research groups in post measurements ( LSD)

\begin{tabular}{|c|c|c|c|c|c|}
\hline Variable & sport & Mean & $\begin{array}{c}\text { Visual } \\
\text { (Expert Modeling) }\end{array}$ & $\begin{array}{c}\text { Visual } \\
\text { (Self-Modeling) }\end{array}$ & Verbal \\
\hline \multirow{3}{*}{ basic skills } & Visual (Expert Modeling) & 7.30 & & .100 & $1.100^{*}$ \\
\hline & Visual (Self-Modeling) & 7.20 & & & $1.000^{*}$ \\
\hline & Verbal & 6.20 & & & \\
\hline \multirow{3}{*}{$\begin{array}{l}\text { Offensive } \\
\text { skills }\end{array}$} & Visual (Expert Modeling) & 7.60 & & .800 & $1.100^{*}$ \\
\hline & Visual (Self-Modeling) & 6.80 & & & .300 \\
\hline & Verbal & 6.50 & & & \\
\hline \multirow{3}{*}{$\begin{array}{l}\text { Defensive } \\
\text { skills }\end{array}$} & Visual (Expert Modeling) & 7.40 & & .300 & .800 \\
\hline & Visual (Self-Modeling) & 7.70 & & & $1.100^{*}$ \\
\hline & Verbal & 6.60 & & & \\
\hline \multirow{3}{*}{$\begin{array}{l}\text { Total skill } \\
\text { performance }\end{array}$} & Visual (Expert Modeling) & 22.30 & & .600 & $3.000^{*}$ \\
\hline & Visual (Self-Modeling) & 21.70 & & & $2.400^{*}$ \\
\hline & Verbal & 19.30 & & & \\
\hline
\end{tabular}

Table (5) shows that there are significant differences between the visual group (Expert Modeling) and the verbal group in (basic skills - offensive skills - Total skill performance) in the direction of the visual group (Expert Modeling), while there were no statistically significant differences between the 
two groups in (defensive skills). There are also statistically significant differences between the visual group (Self-Modeling) and the verbal group in (basic skills - defense skills - Total skill performance) in the direction of the visual group (Self-Modeling), while there were no statistically significant differences between the two groups in (offensive skills).

\section{Discussion}

The results of tables (1), (2) and (3) showed that there were significant differences between pre and post measurements for each of the experimental groups in the skill performance (basic, offensive and defensive skills) in the direction of the post measurement, This demonstrates that the use of feedback using the visual method (the expert modeling, the personal modeling) and the verbal method have positively affected the skill level through the skills (basic, offensive, defensive), where feedback is the information that describes the difference between the specific objective of performance (Hammad, F., 1996, 183), this leads to correct errors and improve the level of performance. This is confirmed by (Mahjoub, W., 2001, 29) that feedback plays an important role in human learning, where Modern teaching methods aim to exploit all senses of the individual in learning, it gives the learner some information about the outcome of his performance, correcting his mistakes until he reaches the correct performance.
(Khayyun, Y., 2002, 94) noted that feedback increases the learners' energy, enhances proper performance, and reduces performance errors. (Rajeh, A., $1979,235)$ noted that feedback is important in that it helps the learner to correct his erroneous responses, make the work more interesting, help to know how much progress in the learning process and help the learner to choose the correct responses.

The change rates of the visual group using (expert modeling) ranged from $(73.81 \%)$ to $(117.14 \%)$, for the visual group using (personal modeling) ranged from (71.43\%) to $(133.33 \%)$, while the verbal group ranged from (63.16\%) to $(94.12 \%)$, while the verbal group ranged from $(63.16 \%)$ to $(94.12 \%)$.

Offensive skills require the appropriate timing along with motor skill, in the performance of each movement in order to achieve the goal of its performance, The researcher believes that the mental picture that emerges of the player through feedback using (expert modeling) may be better in terms of motor skill, speed and timeliness of which in the case of (personal 
modeling), which further helped to improve performance.

Where the approach to the form of optimal performance, is a prerequisite for the learning process. To achieve this, appropriate learning methods must be chosen to increase student performance and effectively contribute to solving technical and motor skills problems. This is consistent with the findings of "Hijazi, M.," (2015) study, which emphasizes the importance of diversity in teaching strategies, through the diversity of teaching activities and methods that fit learning patterns.

The results of tables (4) and (5) showed that there were statistically significant differences between the visual group using the (expert modeling) and the verbal group in the (basic skills - offensive skills - Total skill performance) in the direction of the visual group using (expert modeling).

There were also statistically significant differences between the visual group using (personal modeling) and the verbal group in both (basic skills - defense skills skill level) in the direction of the visual group using the (personal modeling).

The researcher points out that "verbal feedback" may lead to relative dispersion in the student's thinking during performance to focus on the verbal details given by the teacher compared to the "visual feedback" that helps to smooth the skill performance with an optical focus on the performance details. Sometimes lack of information or lack of disclosure, leads to the stumbling process of learning, and may not lead to the correct performance, the teacher gives verbal feedback with the presentation of the form of motion, while the use of modern devices in education and training gives the best dynamic model of skills using the "expert modeling" and gives accurate information about the correct performance.

In addition, the difference in the way of providing feedback affects performance, by observing the learner's performance and comparing it to the teacher's model, the learner discovers his faults when performing the skill and adjusts his performance before stabilizing on the wrong motor paths.

Visual feedback using the (personal modeling) tells the learner how efficient the performance is. And lead to improve technical performance by correcting errors and performance paths during the learning stages, with emphasis on correct performance paths through repetition. It can also become a strong motivation for learning and this is consistent with the study of (Abu Al-Tayeb, M., and al., 2014), Where it reached the presence of statistically significant differences between the verbal feedback group 
and the visual feedback group in the direction of the visual feedback group.

While there were no statistically significant differences between the two groups using visual feedback (expert modeling, personal modeling) in all search variables, which indicate their respective impact in improving skill performance, as it is in the case of visual feedback (expert modeling personal modeling), the teacher uses teaching aids to help the learner understand the skills details well, Where he pointed out (Al-Shaikh, M., 1975, 173) that feedback can be used as a reward when the next information is encouraging to reach the goal, and it acts as an incentive and becomes an important and necessary condition for learning.

\section{Conclusions}

Based on results of this study, the following conclusions can be drawn:

1. There is a positive effect for the use of both visual feedbacks using (expert modeling personal modeling) and verbal feedback on the quality of fencing technique.

2. The use of visual aids in feedback using (expert modeling - personal modeling) has improved the performance of some fencing skills rather than the use of verbal feedback.

\section{Recommendations}

Based on the aim of the study and the collected data, the following implications can be made:

1. The necessity of using visual and verbal feedback methods while learning dueling skills to achieve the best results.

2. Choose the appropriate feedback method according to the age stage and the type of skills provided.

3. Teaching aids using visual displays helps to improve skill performance in fencing, especially in the early stages of learning.

4. Conducting some studies using different feedback methods in learning other sports skills.

\section{References}

Abu Al-Tayeb, M., Halawa, R., Oudat, M., Abu-Arida, A., (2014): The Effect of Visual and Verbal Feedback on Some Kinetic Variables in Sadr's Pool, Educational Sciences Studies, Volume 41, No.2, Jordan University.

Al-Sheikh, M., (1975): dynamic learning, Dar Al-Fikr AlArabi, Cairo.

Beashel, P., Sibson, A., Taylor, J., (2001): The World of Sport Examined,

Nelson

Thornes, 2nd edition, delta place, 27 bath road, 
Cheltenham, GL53 7TH, United Kingdom, ISBN 0174387520.P.

115.

Available at: www.worldof sportsexamined.com.

3/8/2018.

Hammad, F., (1996): Sports training for both sexes from childhood to adolescence, Dar Al-Fikr Al-Arabi, Cairo.

Hijazi, M., (2015): The Effect of Using Mind Maps on the Level of Cognitive Achievement and Skill Performance according to Learning Styles in Fencing, Assiut Journal of Sports Science and Arts "AJSSA", V. (1)., PP 79-93.
Hossam El-Din, T., Abdel-Shakour, M., Helmi, M., (2014): The basics of movement science learning and control locomotive, Markaz Al-Ketab Al-Hadeeth, Cairo.

Khayoun, Y., (2002): Movement Learning between Principle and Practice, Maktabet AlSakhra for printing, Baghdad. Mahjoub, W., (2001): Theories of Learning and Motor Development, Dar Wael for Printing, Publishing and Distribution, Amman, Jordan. Rajeh, A., (1979): Origins of Psychology, II, Dar Al Ma'arif, Alexandria.

Wrisberg, C., (2007): sports skill instruction for coaches, Human Kinetics, ISBN-13: 978-0-7360-3987-1, P.123. 